and probably lasting, value; it is difficult to imagine a more carefully documented and sensibly reasoned account of the way in which ideas on impact theory evolved during the era covered by the book. If it has a failing it is that there is little attempt to put the issue of the acceptance of impact theory into a broader philosophical context. For example, was the opposition on the part of traditional geologists inherited from Lyell, or was it more a reaction to ideas arising outside the mainstream of science?

Compared with Hoyt, Kathleen Mark paints on a much broader canvas, paying more attention to the controversy surrounding "cryptovolcanic" structures, to the increasingly sophisticated study of the erosional pathology of impact craters, and to the continuing search for physical criteria for an impact origin and the structures with which they are associated. To render such material at an avowedly non-technical level is an ambitious undertaking but in this case it has been

\section{Light industry}

\section{John N. Howard}

Land's Polaroid: A Company and the Man Who Invented It. By Peter C. Wensberg. Houghton Mifflin: 1987. Pp.258. \$18.95.

EDWIN Land was born in Connecticut in 1909. Even as a youth he had decided he would achieve fame and fortune in the world of science and technology. After all, had not Thomas Edison, Henry Ford, Alexander Graham Bell and George Eastman - all self-made men, and all then still alive - succeeded by developing practical, usable technology?

When he was 17 his parents sent him to Harvard to study physics. Before the first year was over he had already picked a likely area for a scientific breakthrough: polarized light. Unfortunately he could not immediately see any important practical application. Then, on a vacation trip to New York City he walked into Times Square, saw the bright lights and the glare of automobile headlights, and recognized the need, the opportunity - suppose automobiles had headlights emitting light in one plane of polarization, and windshields of the crossed plane; then, forward vision at night should be unimpaired, but dangerous glare from oncoming headlights would be filtered out. successful. The author handles the basic scientific concepts with confidence and describes them with clarity. Many students, nominally more advanced than the audience for which the book is designed, will nonetheless find it instructive

Both books do justice, in their different ways, to the field of impact theory. Both authors handle observations and ideas with aplomb, but it's probably fair to say that their accounts also tend to neglect the contributions of experimental science. For example, the hypervelocity-impact experiments so beautifully designed and executed by Don Gault surely deserved more than just a footnote mentioning their reproduction of shatter cones. Such carping aside, however, these are excellent books; one or other of them should meet the needs of almost anyone wishing to learn, or learn more, about the history of impact theory.

John F. Kerridge is at the Institute of Geophysics and Planetary Physics, University of California, Los Angeles, California 90024, USA.

Land dropped out of college, took a room in New York, and spent every day at the library reading every published paper about polarized light. An earlier researcher, William Herapath, had found that tiny crystals of iodoquinine sulphate strongly polarized light, but Herapath had been unable to grow them large enough to be useful. Land repeated some of these experiments and determined that he could make the needle-like crystals line up in a magnetic field. Perhaps he could then press them into a sheet of film.

$\mathrm{He}$ went back to Harvard to better laboratory facilities, but just short of graduation dropped out again, this time (with a physics colleague) forming a small company to make polarizing film, which they named Polaroid. By 1935 he had orders from Eastman Kodak for polarizing filters for cameras. Then the American Optical Company introduced Polaroid sunglasses. The business grew, incorporated in 1937 as the Polaroid Corporation, and during the war engaged in defence research and became a successful small company. But the big money of polarized automobile headlights did not materialize: the industry feared that filters on headlights would make them dim.

For Land, the big breakthrough occurred in late 1943, while he was vacationing with his family in New Mexico. He took some pictures of his three-year-old daughter Jennifer and she wanted to see them right away. "They're not ready", he said. She replied, "Why can't I see them now?". Land went for a walk, and within an hour he had in mind the entire process of what needed to be done to make selfdeveloping photographic film possible. The new process of "instant photography", with a working model of the camera, was demonstrated at the February 1947 meeting of the Optical Society of America, and the camera became an instant commercial success.

The company grew and prospered; in 1963 colour film for Land cameras was introduced and in 1972 Polaroid introduced the very sophisticated SX-70 camera, with automatic focusing, automatic aperture for correct exposure and a self-developing print. Through all of the expansion of the company - from a halfdozen employees to as many as $20,000-$ Land remained completely in charge: chairman, president, chief executive officer and chief scientist. Starting in 1975 ,

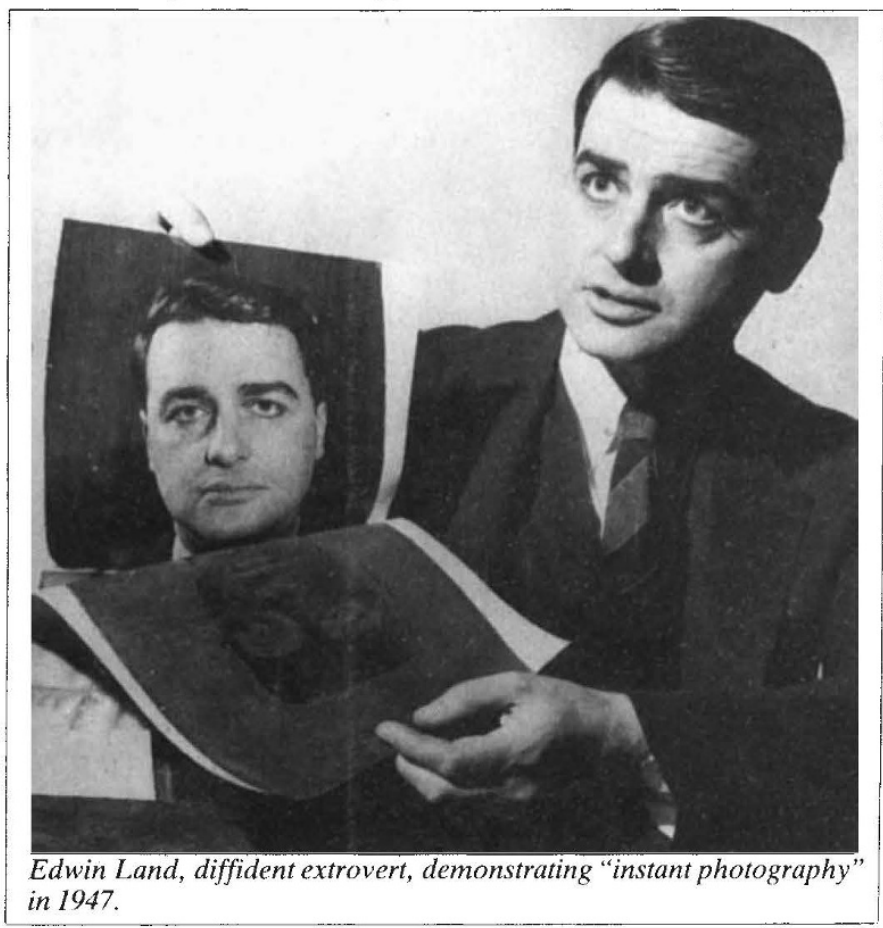
he gradually relinquished these posts, and retired from Polaroid in 1982 at age 73 .

Land is an inventor; his name appears on 533 US patents, second only to Thomas Edison's 1,093. But whereas there are 23 biographies of Edison in print, Wensberg's book is only the second sketch of Land. The book is unauthorized, but it is not by an outsider; Wensberg worked at Polaroid for 24 years, the last several of them as executive vice president. When he told Land he was writing a book about Land and Polaroid, Land said, "That's very disturbing, Peter. Why would anyone want to read such a book?". Wensberg replied, "There's a tremendous interest now in entrepreneurship". "Isn't that an awful word", was the response, "It reminds one of a man standing behind a 
pushcart of bananas".

Wensberg portrays Land as two personalities: as an extrovert he presided at the annual meetings of Polaroid stockholders, which were extravaganzas touting his latest (and invariably best) invention, complete with hyperbole and hoopla; but on the personal level, he is diffident and retiring - even reclusive at least to outsiders.

In writing the book, Wensberg pored over letters and speeches by Land and material from Polaroid annual reports, and collected anecdotes and reminiscences from Land's colleagues and friends. Wensberg narrates key events in Land's life - using so-called "new journalism" techniques - by reconstructing
Land's thoughts and words in conversation. "There are some of Land's words in those stories", he says; "I confess to having enlarged upon them". The prospect of reading reconstructed quotations attributed to him drives Land up the wall: "That's a terrible indignity", he is reported to have said, "I always thought quotation marks were a sacred signal of meticulous honesty".

Honest or not, these "corroborative details add artistic verisimilitude" to a fascinating account of Edwin Land's remarkable achievements.

John N. Howard, 7 Norman Road, Newton Highlands, Massachusetts 02161, USA, is Editor Emeritus of Applied Optics, and also Editor of Optics News, both journals of the Optical Society of America.

\section{Logical conclusions}

\section{Philip Kitcher}

Quiddities: An Intermittently Philosophical Dictionary. By W.V. Quine. Harvard University Press: 1987. Pp. 249. $\$ 20, £ 15.95$.

OVER half a century ago, a young Harvard professor of logic and philosophy published an article expressing doubts about some of the central themes of logical positivism, then in the flush of its new dominance of the Anglo-Saxon philosophical world. That article, "Truth By Convention", was to begin a series of explorations and critiques that would decisively alter philosophical views about logic, mathematics, language and science. Its author, W.V. Quine, would become the dominant figure in post-war Englishlanguage philosophy, first in the United States, and later in England, Scandinavia and Australia. Just as Quine is quoted on the back of the abridgement of the classic Principia Mathematica of Whitehead and Russell - "This is the book that has meant the most to me" - so generations of philosophical logicians, philosophers of language and philosophers can testify that some essay, collection or book of Quine's has been the decisive influence on their own professional researches.

Quiddities is the work of an author who has faith in his own idiosyncratic enthusiasms. Ranging from lucid expositions of philosophical topics that are central to the fields that have intrigued him throughout his career - particularly logic and the philosophy of mathematics - to entertaining and informative details about the quirks of natural languages, it fuses wit with instruction. Fundamental aspects of twentieth-century logic and set theory are explained in ways that will be comprehensible to beginners (while whetting their appetites for further details) and that will be satisfying to the initiated. Quine's

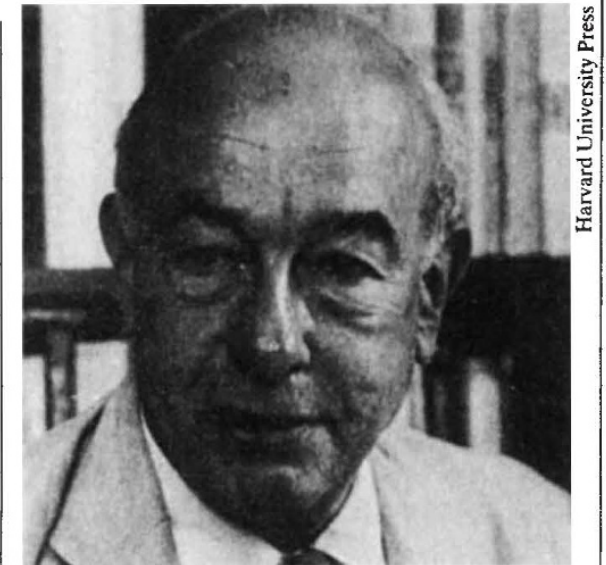

W.V. Quine - idiosyncratic enthusiasms.

talents for exposition are amply displayed in articles on familiar Quinean topics: classes versus properties, classes versus sets, definition, Gödel's theorem, identity, impredicativity, infinite numbers, natural numbers, paradoxes, predicate logic, reference and reification, singular terms, truth, universals, use versus mention, variables. For those who are unaware of the achievements of modern logic, this sequence of articles offers a beautiful presentation of the main staples of contemporary logic, as attractive as it is nourishing.

Perhaps the chief delight of Quiddities lies in the tidbits that are sprinkled throughout the menu. Quine has always been entertained by ordinary language, by the odd relationships among words in different languages, by the ways in which languages change, and the scraps and vestiges that are left behind. Quiddities reveals some of the learning that a lifetime's fascination with words can produce. Readers may be surprised to learn how the violoncello got its name, intrigued by the possibility of using inflections to build ever more complex Latin verbs, struck by Quine's demonstrations that gender in language can sometimes be used to disambiguate and can sometimes lead to intra-linguistic tension, and frankly repentant about their past usages of 'agenda' and 'media' (both are Latin plurals corrupted as singulars). Quine wears his learning lightly, and the grace of his discussions reflects his love of the whimsy of language.

Quiddities is an "intermittently philosophical dictionary" in two senses. Not only is the philosophy punctuated by articles on matters linguistic, but the treatment of philosophical issues is itself quite selective. There are only occasional ventures into philosophical territory that Quine has not explored in his more academic writings, and these ventures seem to me rather disappointing. For example, in discussing the hoary topic of free will, Quine, like many other philosophers, favours the view that freedom is compatible with psychological determinism. Though all our actions and decisions may be completely caused, that does not necessarily deprive us of freedom. What matters is the way in which they are caused. One who adopts this view must explain what kind of causation allows for freedom, and it is in discharging this task that Quine seems to me to go astray.

David Hume offered the simplest account: we act freely when our actions are caused by our beliefs and desires. Yet it has seemed to numerous philosophers that this is far too simple, for there are individuals who are compelled by their desires - kleptomaniacs, alcoholics, compulsive smokers - and, though they satisfy their desires, they do not act freely. Another condition must be satisified to ensure freedom, a condition that will differentiate those who are psychologically disabled from those whose considered desires are manifested in their behaviour.

Quine has no time for such complications. He offers the original Humean solution, and, in response to the possibility of "ill health of the offender's decisionmaking faculties", declares that psychological disability can provide no excusing grounds. This blunt treatment of the problems has the advantage of simplicity, but it surely errs in overlooking the existence of coercion from within as well as from without. Moreover, in explicitly frowning on the use of insanity pleas, it runs the risk of supporting much injustice.

Ultimately, though, questions of freedom, morality and punishment are not at the centre of Quine's thought. For many readers, Quiddities will serve as a superb introduction to central issues in contemporary thinking about logic, mathematics, language and science, an introduction that may lead them on to appreciation of Quine's half century of seminal writings. Aficionados will enjoy the witty reformulations of familiar themes and find a bonus in learning about the quintessential quirkiness of natural language.

Philip Kitcher is a Professor in the Department of Philosophy, University of California, San Diego, La Jolla, California 92093, USA. 